\section{Ypthima kedarnathensis Singh, 2007 (Lepidoptera: Nymphalidae: Satyrinae) from the Kumaon Himalaya, India}

\section{Peter Smetacek}

Butterfly Research Centre, The Retreat, Jones Estate, Bhimtal, Nainital, Uttarakhand 263136, India

Email: petersmetacek@rediffmail.com

The description of the butterfly Ypthima kedarnathensis Singh, 2007 was based on three specimens taken in the Kedarnath Musk Deer Reserve, Garhwal, Uttarakhand from two localities within $10 \mathrm{~km}$ of each other. It belongs to the $Y$. sakra Moore group of the genus and is distinguished from the sympatric $Y$. nikaea Moore mainly by the additional ocellus on the hind wing between veins 4 and 5, which is conjoined to the large ocellus in space 5 on the verso surface and is clearly marked on the recto surface.

The Lepidoptera of Nainital District, mainly Nainital Town and the Bhimtal Valley, have been surveyed for over half a century. In 2007 and 2009, Lepidoptera of the southern face of the Gagar range were surveyed, mainly at $29^{\circ} 26^{\prime} 4^{\prime \prime} \mathrm{N} \& 7^{\circ} 35^{\prime} 40^{\prime \prime} \mathrm{E}$. Among other Lepidoptera, several specimens of the $Y$. sakra group were recorded. Critical examination of these and other specimens recorded locally resulted in the following diagnoses.

\section{Material and Methods}

A series of 27 specimens of the Ypthima sakra group in the author's personal collection was examined. The

Date of publication (online): 26 December 2010

Date of publication (print): 26 December 2010

ISSN 0974-7907 (online) | 0974-7893 (print)

Editor: Arun P. Singh

Manuscript details:

Ms \# 02574

Received 16 September 2010

Final received 30 October 2010

Finally accepted 25 November 2010

Citation: Smetacek, P. (2010). Ypthima kedarnathensis Singh, 2007 (Lepidoptera: Nymphalidae: Satyrinae) from the Kumaon Himalaya, India. Journal of Threatened Taxa 2(13): 1390-1391.

Copyright: (c) Peter Smetacek 2010. Creative Commons Attribution 3.0 Unported License. JoTT allows unrestricted use of this article in any medium for non-profit purposes, reproduction and distribution by providing adequate credit to the authors and the source of publication.

Acknowledgements: This work was funded by a Rufford Booster Grant for which I am grateful to the Rufford Small Grants Foundation, U.K. am indebted to Manoj Chandran, IFS and Kedar Tokekar, Pune, for coordinates.

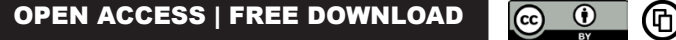

individuals comprising this series were collected over the past 37 years in Nainital District of Uttarakhand, India (Image 1). A single specimen was taken in Almora District. They were identified as:

Ypthima nikaea Moore: 23 exs.: Forewing length: 22$25 \mathrm{~mm}$. Expanse (forewing tip to centre of thorax $\times 2$ ) $=$ 48-54 mm. Coll. et det. Peter Smetacek.

(a) Bhimtal, 29021'17"N \& 79032'34" $\mathrm{E}, 1500 \mathrm{~m}$, Nainital District, Kumaon, Uttarakhand: 26.viii.1973 (Ynikaea1), 21.vi.1974 (Ynikaea3), 21.v.1975 (Ynikaea4), 23.v.1975 (Ynikaea5), 05.ix.1975 (Ynikaea6), 16.v.1976 (Ynikaea7), 13.x.1976 (Ynikaea8), 16.v.1982 x 3 (Ynikaea9-11), 12.ix.1983 (Ynikaea12), 08.viii.1991 (Ynikaea13), 29.v.1994 (Ynikaea14), 30.v.1994 x 2 (Ynikaea21-22), 12.vi.1994 (Ynikaea23); (b) Sattal, 29021'09"N \& 79³1'67"E, 1200m, Nainital District, Kumaon, Uttarakhand 05.vi.1974 (Ynikaea2); (c) Below Gagar Pass, Maheshkhan, 29024'46"N \& 79032'39"E, 2200m, Nainital District, Kumaon, Uttarakhand 29.v.1994 x 6 (Ynikaea15-20); (d) Kukuchhina, 29050'24"N \& 79027'13"E, 2200m, Almora District, Kumaon, Uttarakhand 6.vi.2010 (Ynikaea24).

Ypthima kedarnathensis Singh (Images 2 \& 3): 1 ex.: Forewing length: $23 \mathrm{~mm}$. Expanse (forewing tip to centre of thorax $x$ 2) $=50 \mathrm{~mm}$. Leg., coll. et det. Peter Smetacek.

Below Gagar Pass, Maheshkhan 2200m Nainital District, Kumaon, Uttarakhand, 29.v.1994 (Ykedarnathensis1).

Three individuals from Bhimtal could not be placed.

\section{Discussion}

Although $Y$. kedarnathensis was described on the basis of wing pattern, which is notoriously variable in this sub-family, subsequent comparisons of male genitalia of $Y$. sakra sakra, Y. nikaea and a paratype of $Y$. kedarnathensis confirm that $Y$. kedarnathensis is indeed specifically different from the two former species (unpublished data).

The present record of $Y$. kedarnathensis constitutes an eastward extension to the known distribution of the species. Of interest is the fact that it has not been recorded from below $1600 \mathrm{~m}$, where butterflies have been recorded over a period of more than 40 years. It therefore appears to be restricted to the region above $1600 \mathrm{~m}$. Like the type locality, the present locality also has dense subtropical broadleaf forest with Quercus leucotrichophora A. Camus (Fagaceae) and Rhododendron arboreum Smith (Ericaceae) as dominant species. Singh (2007) recorded his specimens between 1600 and $1800 \mathrm{~m}$. The present record from $2200 \mathrm{~m}$ also constitutes an extension to the known altitudinal distribution of this species.

Singh (2007) mentioned a wingspan of $40-45 \mathrm{~mm}$ for the type material of $Y$. kedarnathensis. The present 

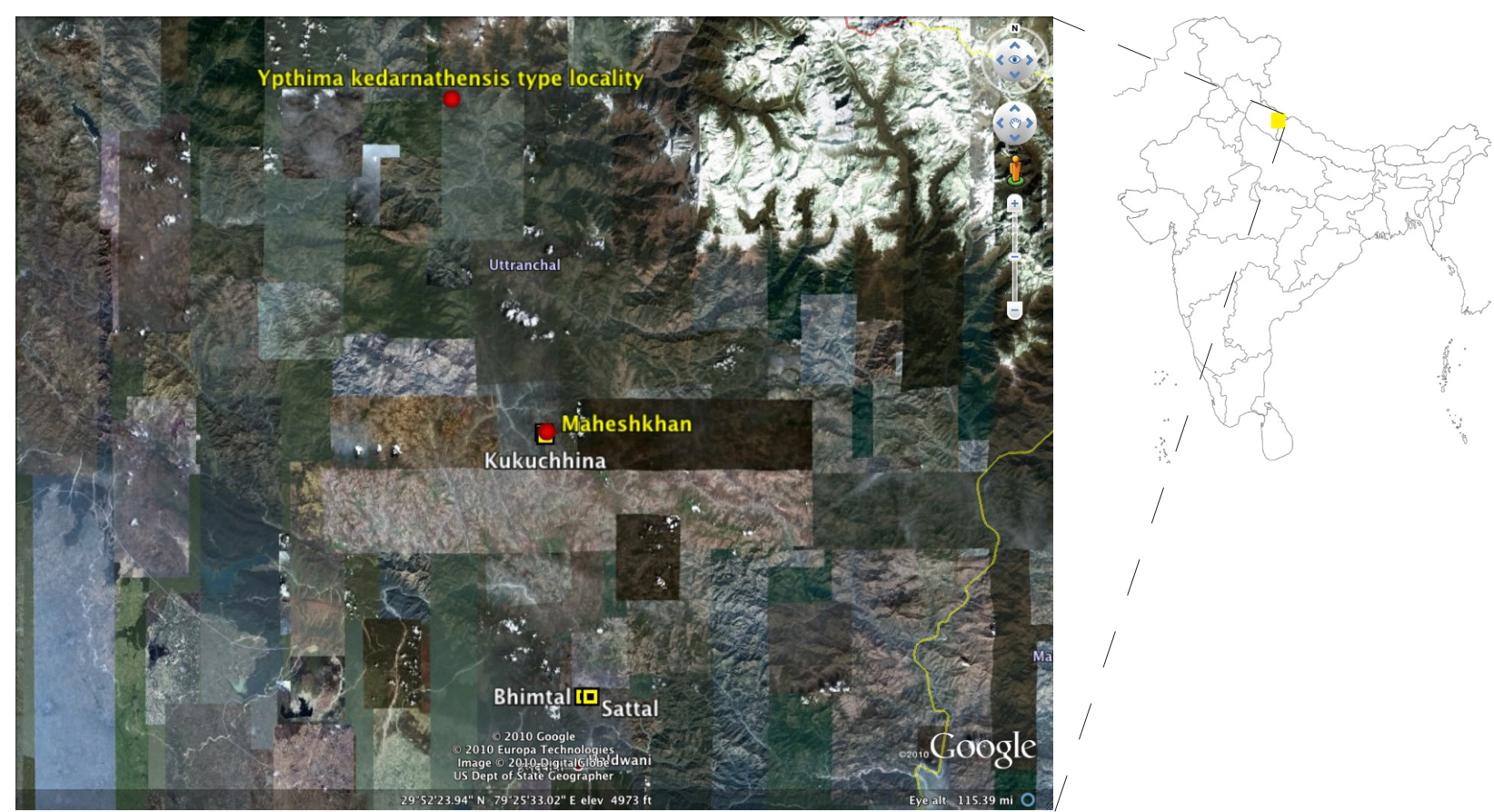

Image 1. Localities indicating the known distributions of Ypthima kedarnathensis (red dots) and Y. nikaea (yellow squares). Both the species were collected from Maheshkhan.

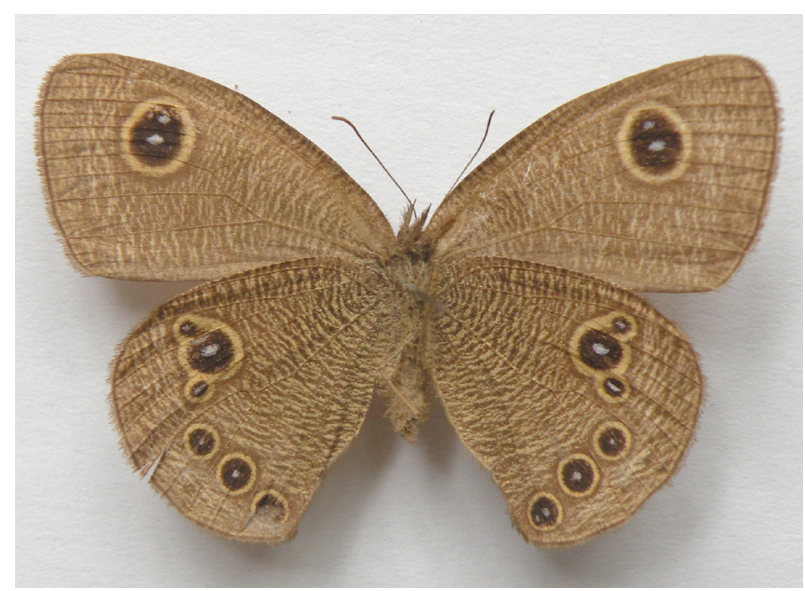

Image 2. Yphthima kedarnathensis A.P. Singh verso.

Below Gagar Pass, Maheshkhan 2200m, Nainital District, Uttarakhand (29.v.1994).

specimen has an expanse of $50 \mathrm{~mm}$ but this is probably because of difference in measurements, in that the type material was measured directly from forewing tip to forewing tip (A.P. Singh pers. comm.) while the specimen examined in the present study was measured from the forewing tip to the centre of the thorax and the resulting figure doubled.

For Y. nikaea, Evans (1932) gives an expanse of 45$50 \mathrm{~mm}$. Some specimens examined in the present study are larger than this, with an expanse up to $54 \mathrm{~mm}$.

The altitudinal distribution of $Y$. nikaea in the Kumaon

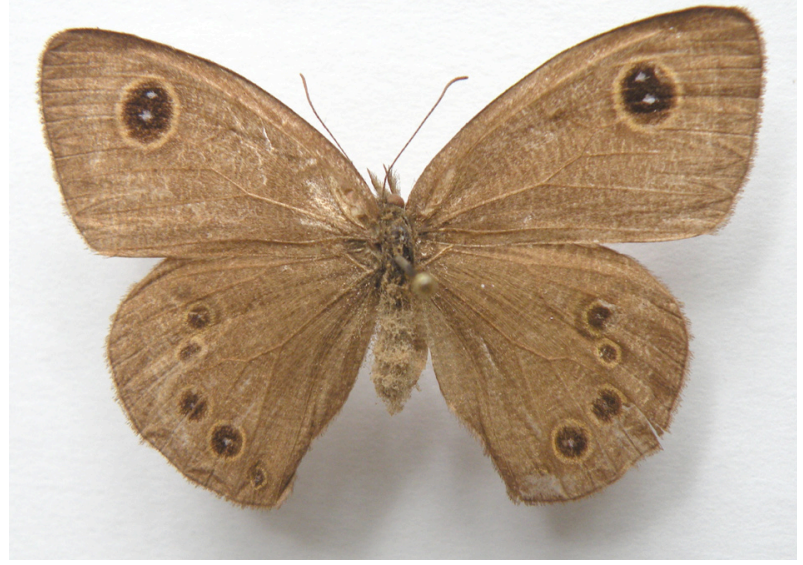

Image 3. Yphthima kedarnathensis A.P. Singh recto. Below Gagar Pass, Maheshkhan 2200m, Nainital District, Uttarakhand (29.v.1994).

Himalaya extends from $1200 \mathrm{~m}$ to at least $2200 \mathrm{~m}$ and probably higher. I have seen them on Gagar Pass (2400m) but do not have a specimen to support the observation.

\section{REFERENCE}

Singh, A.P. (2007). A new butterfly species of the genus Ypthima Hübner (Nymphalidae: Satyrinae) from Garhwal Himalaya, India. Journal of the Bombay Natural History Society 104(2): 191-194. 